\title{
Opinion \\ The culture and practice of longline tuna fishing: implications for seabird by-catch mitigation
}

\author{
GRAHAM ROBERTSON
}

\section{Summary}

The development of practical approaches to seabird by-catch reduction in longline tuna fisheries is dependent upon knowledge of fishing practices and the cultural and vocational nuances of fishermen. This overview, drawn from information gathered on Japanese tuna vessels in Australian waters, describes the Japanese method of tuna longlining and lists possible reasons for the reluctance shown by tuna fishermen in the adoption of measures to reduce the incidental take of seabirds. While the focus is on Japan there are reasons to believe that tuna fishing for long periods on the high seas is a culture of its own that transcends nationalities. The acceptance of change in fishing cultures, unless imposed by economic necessity or direct government policy, is slow. The overview also makes some suggestions for future efforts to reduce seabird deaths in longline tuna fisheries.

\section{Introduction}

Of the various kinds of longline fishing practices (see, for example, Bjordal and Lokkeborg 1996) one of the most dangerous to seabirds is mid-water pelagic fishing for tuna. This fishery concentrates near ocean fronts and continental shelf breaks, which are also favoured by foraging seabirds. Vessels deploy large numbers of baited hooks on long, lightweight branch lines that sink slowly and are vulnerable to attack by seabirds (in contrast, demersal longliners deploy short branch lines on a weighted mainline which sinks relatively quickly). Tuna fishing is conducted by the domestic fleets of various nations and by large fleets from Japan and other Asian nations which have the capacity to fish almost anywhere in the world for the lucrative Japanese raw tuna markets. In the Southern Hemisphere the Japanese longline fishery for southern bluefin tuna Thunnus maccoyi is perhaps the fishery with the greatest incidental take of albatrosses and other seabird species (Bergin 1997 and references therein).

To a Japanese tuna fisherman, longline fishing represents the means to a decent living, the opportunity to follow a family tradition and the chance to be an officer or even the fishing master of a tuna vessel. It also means ten-and-a-half months a year at sea, long working hours, isolation from family life and almost total exclusion from a normal social existence. To a seabird conservationist longline fishing for tuna is an activity that causes unacceptably high mortality rates of seabirds. Add to these different perceptions the unusual characteristics of long- 
line fishing and the interactions between different cultures and value systems and you have a recipe for misunderstanding and potential confrontation, rather than for collaboration to implement mutually beneficial solutions. That there has existed an element of cooperation between tuna fishermen and conservationists is largely a result of attempts by the latter to understand the activities and cultures of the former, for this is seen as a necessary prerequisite to the development of seabird-friendly fishing techniques and their adoption by fishing vessels.

Without knowledge of longline fishing, or the cultural background of fishermen, it is not possible to understand why, in the presence of effective and seemingly easy-to-use mitigation measures (see Alexander et al. 1997), seabirds continue to be caught in large numbers in tuna longline fisheries. This paper describes the Japanese method of longline fishing, lists some issues that have the potential to hinder the adoption of mitigation measures by fishermen and makes suggestions that may aid in developing solutions to the problem. The perspectives given pertain to the Japanese longline tuna fishery because of my experience gained on their vessels, the large size of their fleet (about 600 longline vessels), the global nature of their fishing effort (e.g. Hori 1996), the high death rates of albatrosses reported in the Japanese fishery (Brothers 1991, Murray et al. 1993, Bergin 1997) and the importance of Japan in global tuna markets (e.g. Hori 1996). However the perspectives could apply equally to other nations that use the same fishing methods (e.g. Taiwan, Indonesia, Republic of Korea) to supply Japanese tuna markets.

\section{Longline fishing for tuna}

\section{The Japanese method}

A Japanese longline tuna vessel is essentially a huge freezer sitting atop a very large fuel tank. A vessel may be $40-50 \mathrm{~m}$ in length, weigh $200-300$ tonnes, carry $190 \mathrm{~m}^{3}$ of diesel fuel and cruise at about 10 knots. It can carry about 250 tonnes of frozen fish in its freezers and has a complement of about 20 crew members. The freezer space and fuel capacity enables longliners to stay at sea for several months of continuous fishing, and vessels carry a sophisticated array of electronic equipment to aid navigation and to maximize fishing efficiency.

A Japanese longline vessel fishes with a continuous rope or monofilament mainline up to $130 \mathrm{~km}$ in length (Figure 1). This mainline is suspended in the water column at predetermined depths by floats spaced $300 \mathrm{~m}$ apart. Up to 3,200 hook-bearing 35 -m-long branchlines are suspended at $35-\mathrm{m}$ intervals along the mainline and each hook fishes at a different depth depending on its position between the floats and the amount of slack in the mainline, which is influenced by sea conditions. Hooks are baited with mackerel or squid and the fishing depth varies from 50 to $200 \mathrm{~m}$. Fourteen radio beacons are deployed along the mainline and these enable vessels to steer automatically when hauling and to locate the mainline after line breakage. The mainline is usually deployed in a straight line or some other configuration, depending on sea conditions, previous fishing successes and the desire to avoid line tangles with nearby vessels. Vessels may fish either solitarily or as a fleet, with favoured fishing areas sometimes being fished by more than 100 vessels situated less than $5 \mathrm{~km}$ apart. Annual catch rates of southern bluefin tuna vary from 1 to 5 fish per 1,00o hooks (Hori 1996). 


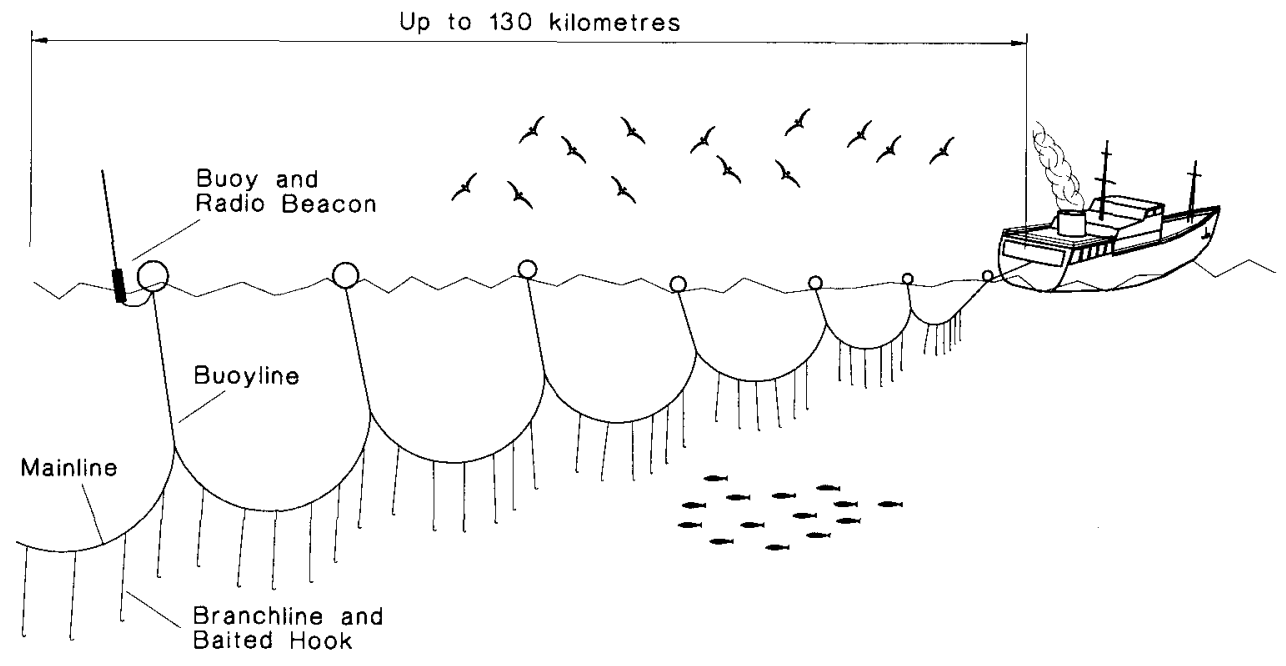

Figure 1. Structure of the longline used by Japanese vessels to catch southern bluefin tuna.

\section{Processing tuna for sashimi}

In the Southern Hemisphere the pride of the Japanese tuna catch, due to its high market value, is the southern bluefin tuna. To achieve the maximum market value each tuna must be treated in a special manner once landed on deck. A southern bluefin tuna may be $2 \mathrm{~m}$ long and weigh $300 \mathrm{~kg}$, and if landed in a healthy condition may struggle with enough power to lift its body clear of the deck. Such intense struggling leads to a reduced market value (see below) and to minimize struggling the tail of a landed tuna is quickly removed. The fish is then dragged onto a carpet nailed to the deck, evidently to induce calmness. The ice master, the crew member responsible for fish quality, then removes a wedge of skin over the pineal window in the head to allow access to the brain and spinal chord. A $1.5 \mathrm{~m}$-length of wire is then rammed repeatedly through the brain and spinal column to destroy the central nervous system; this is referred to as "administering quietus" to the fish, and is meant to destroy the processes of life deep within the body. Blood vessels near the pectoral fins are punctured and the gills and guts are irrigated with water for several minutes to remove blood from the meat. After gutting and gilling the fish is washed and stored overnight in a freezer at $-60^{\circ} \mathrm{C}$. The following day the frozen fish is enveloped in a thin layer of ice (by washing in fresh water) to minimise moisture loss during the several months that might elapse between capture and delivery to market.

There is logic to this method of killing the tuna. The colour and tenderness of tuna meat influences the market value. When a landed tuna struggles, glycogen, fat and protein are consumed and waste matter (e.g. lactic acid, a by-product of anaerobic respiration) quickly accumulates in the meat. This lowers the $\mathrm{pH}$ of the muscle, bleaches the meat and reduces its appeal to the consumer. The colour of the meat is also affected by a condition called "burn". The body temperature of southern bluefin tuna is about $27^{\circ} \mathrm{C}$, considerably higher than that of the sea in which it swims, and once landed on deck the tuna's temperature-preserving 
ability causes a build-up of heat deep in the fishes body; this denatures (burns) protein and changes the colour of the meat. Colour changes are minimized by the prevention of struggling; hence the importance of the swift removal of the tail, the placement of the fish on the carpet and the destruction of the central nervous system.

\section{Life aboard a Japanese tuna vessel}

Life for the crew on a Japanese vessel is cramped and the work intense. Ten-anda-half months each year may be spent at sea and while on fishing grounds the longline is shot and hauled daily until the freezer is filled or the quota is met. Each day after the line is hauled (in the early hours of the morning) the crew baths and sleeps while the fishing master directs the ship to his preferred line setting position. Following about two hours sleep five crew members commence line setting which usually starts before daybreak and lasts about five hours. At the end of line setting the mainline is detached from the vessel with the end of the mainline attached to a radio beacon. After line setting the entire crew sleeps for about two hours while the boat drifts. Around noon the crew rises, the vessel tracks onto the last radio beacon deployed during line setting and line hauling commences. Hauling lasts 12-14 hours, ending in the early hours of the following morning. At the end of the haul the crew sleep for about eight hours before the next haul commences, and five crew members must rise after only an hour or two and re-set the line. This scenario typifies life on a longliner: except for time spent in port and travelling to fishing grounds the crew on a Japanese tuna vessel do little else but work, eat and sleep, and all are usually deprived of the last.

\section{Anecdotes}

The following anecdotes, which are based on personal experience as a fisheries observer on Japanese longliners, further illustrate aspects of the Japanese fishing practice. The examples highlight the work conditions, some aspects of modern day tuna fishing and the circumstances that may hinder the execution of observer duties.

\section{The dangers of longlining}

Vessels fish in all weather conditions. One night we fished at $45^{\circ} \mathrm{S}$, in the northern part of the Southern Ocean, in driving wind and rain and in seas high enough for waves to break over the bow of the ship. The crew wore crash helmets and mesh face masks to protect their faces from hooks which flew across the deck when the branch lines broke free from the catch under tension. Waves repeatedly broke over the deck upending some of the crew and drenching everybody. That night the crew worked in a frenzy of activity and white water. The mainline broke eight times and became badly tangled (as it usually did in big seas) and no tuna were caught, although 260 sharks were landed. The next morning, 24 hours after the haul had commenced, the deck was covered in a mountain of tangled fishing line, dead 
sharks and worn-out crew members still working. Fortunately no one was hurt in the big seas, but a report from a nearby vessel revealed that a seaman had had his eye badly hooked while hauling a shark and needed to be taken to port for surgery.

\section{Modern-day fishing}

The tuna industry became established in Japan in the 1700 when technology was simple, overfishing was impossible and concern about bycatch unheard of. Two centuries later there is scant connection to the ways of old. On a modern longliner only the men working the electric reels (used to retrieve branch lines) conduct a practice reminiscent of the ancient craft of fishing (the deployment and retrieval of fishing lines), the current version with its industrial approach lacking the simplicity of the old. A few metres behind the men on the reels and responsible for processing the catch are the slaughtermen, with a rack of well-used knives, meat cleaver and gaff nearby. Here fish of all shapes and sizes are treated the same. Once landed a southern bluefin tuna is relieved of its tail and some of its fins, has a hole dug in its head to allow access to its brain and is cut near the ventral fins to drain blood from the carcass while the heart is still beating. When being dressed anything that might be unsightly to the buyers at the fish market is carefully manicured away by skillful use of a flensing knife. A southern bluefin tuna on the carpet is now revered for the enormous price it will fetch on a fickle market and all consideration of the fish is in respect of that. Apart from the occasions when the fishing master pours a bottle of sake over the mainline - the only hint of contact with the metaphysical world that produced nature's bounty in the first place - there is no time for special ceremony when a big tuna is caught that might befit its pride of place in the ships freezer or acknowledgement that it is keeping the ship, the crew and their families at home afloat economically. Once on deck the prize of the deep is reduced to a piece of organic matter where its value, and the respect given to it by people, is no longer related to its role in the natural order of the ocean but to its colour and taste in a restaurant.

Apparent nonchalance by today's tuna fishermen to the harvesting of species possibly revered by previous generations is doubtless a by-product of market forces fuelled by an ever increasing human population (which dictates an industrial approach to fishing), and these are some of the issues at the heart of problems such as fish stock depletion and seabird by-catch.

\section{Observers}

An observer on a Japanese tuna vessel can be in an awkward position if value judgements are necessary on the fishing operation. The observer is in a foreign domain, he/she receives hospitality from the crew, lives off the vessel's resources and an element of camaraderie may 
develop with crew members. This camaraderie can create conflicts of interests when certain fishing practices can be considered to be unethical. On one vessel the fishing master mentioned with gusto that small tuna would be cut loose so the freezers could be filled with large, high-value fish (this is referred to as "high grading"). At the time this practice was permitted by the Australian government. It meant that released fish were freed with the hook in their mouth and several metres of fishing line attached. The fishing master, captain and radio operator were adamant about their desire to high grade, and it was clear that to oppose their view, or even suggest a modification, would cause a major confrontation (there is always the thought that after you leave they will do what they want anyway). They insisted that the hook didn't affect the fish and I eventually accepted their decision provided they cut the line at the mouth of the fish (meaning they had to gaff the fish to within touching distance, which involved extra work) and provided they didn't gaff it in the eye, to ensure it survived. Mid-way through the discussion the fishing master went stony silent and was probably thinking that despite much time and education on board his vessel a dark side to the observer was emerging. Extensive arm waving and working of the English-to-Japanese dictionary ensued and the abovementioned compromise was reached, but not before it became clear that one would face ostracism by the crew for the remainder of the cruise.

High grading was something the crew felt strongly about, since it affected the economics of fishing, and they were outspoken on the matter. Discourse between observers and crew on less heartfelt matters, such as education on seabird bycatch, may be less forthcoming and may be met with disinterest, tokenism or negative feedback of a subliminal nature. The effect of this on the execution of the observer's tasks will depend on the personality and commitment of the observer, and may easily result in equivocation on issues affecting seabird conservation.

It is clear from the descriptions above that life for the crew aboard a Japanese longliner involves exclusion from a normal social existence, long and intense working hours, threats to personal safety, inter-personal loyalty (borne from common hardship) and single-mindedness about catching tuna. Against this background it is not surprising that seabird by-catch has in the past been overlooked as an issue deserving of attention and that requests to employ mitigation measures have been treated with varying degrees of apathy by tuna fishermen.

\section{Potential constraints on the adoption of mitigation measures}

Because a variety of mitigation measures exist (Alexander et al. 1997 lists nine measures that have been shown to be effective) conservationists may be lulled into thinking that Japan and other nations using the Japanese fishing method are taking seabird by-catch seriously enough. It would be a mistake to reach this conclusion without an objective look at the evidence. Two examples serve to 
disappoint, and both indicate a haphazard attitude by fishermen to reducing bird strike. The first concerns the use of bird scaring streamer lines. These are simple, inexpensive items requiring minimal effort to deploy and retrieve, and if properly used may reduce bird strike by up to 70\% (Klaer and Polacheck 1995). Bird lines are absent from some vessels and others may be deployed in such a way as to have minimal effect on seabird by-catch. The second example concerns the increased use of bait-throwing machines (currently used by $60 \%$ of Japanese longline vessels), which is often cited as evidence that fishermen are beginning to take seabird by-catch seriously. Bait throwers were developed to be used in concert with bird lines so bait could be deployed consistently and in all weather and sea conditions under the protection zone of the bird scaring streamers (by straightening the branch line during line shooting, bait throwers also help reduce the incidence of line tangles). However, some vessels ignore the position of the bird line when deploying bait mechanically, which suggest that vessels may purchase bait throwers for reasons other than saving birds (e.g. to save labour). Clearly, the existence of proven methods does not necessarily mean they will be adopted and used properly by fishermen.

There may be a number of reasons for the reluctance shown by Japanese fishermen in adopting mitigation measures. First, it is likely that many Japanese fishermen, and tuna fishermen from other nations, consider that longline fishing is not to blame for decreases in seabird populations. This perception probably stems both from the inability of conservationists to prove scientifically that longline fisheries are the culprits (the evidence is circumstantial - overwhelming but, nonetheless, circumstantial) and because any hypothesis that will offer fishermen an alternative to their own responsibility tends to be grasped. That other factors, such as chemical contaminants (e.g. Ludwig et al. 1997) and plastic ingestion (e.g. Auman et al. 1997), have been shown to have only minor effects on albatrosses compared with longline fishing, and that no other plausible agents of mortality are known to exist to explain the population decreases (Alexander et al. 1997), may not be enough for sceptical fishermen.

Second, even fishermen who concede that bird strike is a problem may believe the issue is overrated. This perception could arise because of a lack of interest in seabird conservation per se (this would be expected, given the wastage of bird and non-bird by-catch and its acceptance by the fishing industry) and because of ignorance of the magnitude of bird by-catch. The low strike rate of birds tends to mask the severity of the problem. A strike rate of, say, 0.4 birds/1,00o hooks deployed, detected during the line-hauling stage of fishing, means that for each daily complement of 3,00o hooks deployed only about one bird, on average, will be caught. This is hardly a catch rate to attract attention. Also, birds are often cut from the line without landing, making the problem even less obvious to other crew members. Nonchalance about bird deaths is probably compounded by the intensity of the focus on catching fish, rather than on bird issues, during both line hauling and setting, the intense work routine (which is not conducive to incidental observations of birds stealing bait from hooks), work pressure and tiredness, particularly during the line-setting stage of fishing when bird strike usually occurs. Also, it is doubtful if fishermen make the mathematical connection between the strike rate of seabirds per fishing vessel and the vast number 
of hooks deployed annually by all tuna vessels in the southern oceans of the world (50-100 million in recent years), which yields estimates in the order of tens of thousands of birds killed annually by longline tuna vessels.

A third reason may pertain to economics. When the values of primary industry and conservation collide it is usually those of the former that prevail; this is especially true in times of economic hardship. The current relatively low prices for tuna and the high costs of labour, fuel and licence fees for fishing in national economic zones, are forcing Japan to reduce the size of its tuna fleet, to employ foreign crew and to purchase increasing amounts of tuna from other countries (Hori 1996). Global depletion of tuna stocks (Hayes 1997) is also adding to economic woes. While some seabird by-catch mitigation measures are simple and inexpensive (see above) others, such as setting lines at night, theoretically include risk of reduced fish catches. Periods of reduced profitability are not seen as being conducive to experimentation with the use of alternative methods or times of fishing. This does not, of course, excuse failure to use measures which are easy to implement and known to greatly reduce bird deaths and bait loss.

Fourth, Japan, along with Australia and New Zealand, is a signatory to the Convention for the Conservation of Southern Bluefin Tuna. Among other things, this sets fishing quotas to ensure the optimal use and long-term viability of southern bluefin tuna stocks. As a CCSBT member Japan is obliged to abide by quotas for high seas fisheries (those outside national economic zones) and to conduct administrative duties associated with the reporting of catches and other activities. Vessels from non-CCSBT states (e.g. Taiwan, Indonesia and the Republic of Korea), which may fly flags of convenience to shirk responsibilities, are free to do as they wish (e.g. non-compliance with high seas quotas and reporting of fish catch statistics). This singling out of Japan may be a source of irritation to Japanese fishermen and may make them less compliant when dealing with seabird by-catch issues.

A fifth constraint on the adoption of mitigation measures may be related to tradition. Japanese fishermen have employed the same fishing practices for several decades and may be loath to change a practice that has worked for them in the past, particularly if change involves using fishing methods suspected of compromising fishing efficiency and income.

\section{Challenges for the future}

While one can feel sympathy for those facing economic hardship, including tuna fishermen and their families, seabird conservationists have the responsibility of minimizing seabird deaths in longline fisheries and improving the status of threatened species; these responsibilities must remain foremost in their minds. Short of a cultural change by longline tuna fishermen toward a more holistic approach to fishing and the environment, the safest bet would be to assume that many tuna fishermen care little about seabirds and will continue to be casual about the use of mitigation measures. In light of this despondent assessment where, then, does this leave the seabird conservation effort? In considerable trouble I'd say. Clearly, a panacea to the problem has not yet emerged and until it does we are left with the promotion of existing measures and pressure on tuna fishermen via the various administrative, legislative (see Haward et al. 1997) and 
diplomatic processes to use best practice. In addition to those processes action on the following issues may contribute to the development of long-term solutions to the problem.

The first concerns the role of the fishing industry in by-catch mitigation research. Since the mid-1980s, when longline tuna fishing was identified as a cause of seabird mortality, tuna fishermen seem to have shown little initiative in developing their own solutions and have largely relied on government employed conservationists to address the problem. An alternative to this lopsided derangement would have the tuna industry taking sole responsibility and conservationists taking none. The reasonable argument is that conservationists and fishermen both contribute to resolving the problem in a manner commensurate with their skills and finances. Conceptually the issue is relatively straightforward and well within the grasp of innovative engineering. Fundamentally what is needed are methods to greatly reduce the time that baited hooks flounder near the surface or, alternatively, devices (immune to misuse by fishermen) that set lines underwater. Nations with the technological prowess, engineering capabilities and fishing histories of Japan, Taiwan and the Republic of Korea have the wherewithal to develop practical measures along these lines. Willy-nilly approaches to mitigation with semi-plausible ideas are not indicative of real effort, and it is time the tuna industry committed serious financial and human resources to solving the problem.

There are many benefits to the tuna industry in their acceptance of this responsibility. They will be seen, rightly, as leading the effort to reduce by-catch and so would have an enhanced position in the public view. Second, research and implementation of relevant findings must increase the practical knowledge base of the industry and have efficiency benefits as fishing techniques become more selective.

The second challenge concerns the worldwide dearth of scientists studying albatrosses, the group of birds most commonly taken by tuna longline fisheries. Albatrosses offer great potential for study. They are reasonably abundant, widely distributed in both Northern and Southern Hemispheres, breed at relatively accessible places, are faithful to natal sites and are large enough to carry instruments. Further, since all species are probably affected by fisheries a practical reason (as against esoteric) exists for the soliciting of research funds. In spite of these facts and the immediacy of the conservation concerns there are few scientists currently conducting albatross studies (for example the USA, a nation with a large research contingent, boasts only one practising albatross biologist). An increased involvement would not only lead to better knowledge of albatross biology but to a greater number of people with expert knowledge willing to become actively involved in albatross conservation issues, including mitigation research. In the long term albatrosses, fishermen and conservation efforts can only benefit.

The third challenge concerns the development of a network of communication between fishing masters (responsible for the way vessels fish) and the managers of fishing companies (to whom fishing masters are responsible) on the one side, and seabird conservationists on the other, in all areas of the world where tuna longline vessels dock and company managers reside. The establishment of this network will not be an easy task, particularly in countries without fisheries observer programmes, but will be necessary to allow dialogue, and the potential devel- 
opment of rapport on a personal level, between seabird conservationists and the fishing industry; this will be essential in the long term to expedite the rate of adoption of seabird-friendly fishing practices by fishing vessels longlining for tuna.

The final challenge pertains to the low number of people in the world who have studied seabird by-catch on tuna vessels and the current inadequate levels of funding for mitigation research; these issues have, I believe, limited progress on seabird by-catch reduction more than any others. To the average person longline tuna fishing is shrouded in mystery, and without first-hand experience on vessels with fishermen plying their trade it is difficult, if not impossible, to identify research questions on by-catch reduction and to develop technologies that are effective and relevant to fisheries. Required are people with a seabird conservationist's heart, an engineer's mind, a fertile imagination and appropriate financial backing. Unless serious effort is made to involve more people in mitigation work and more funds are made available for engineering research, the world's oceans will be far more desolate in future, with fewer albatrosses plying the waves.

\section{Acknowledgements}

Comments by Harry Burton, John Croxall, Eric Woehler, Hiroshi Hasegawa, Thorn Smith and Roger Kirkwood improved a draft.

\section{References}

Alexander, K., Robertson, G. and Gales, R. (1997) Incidental mortality of albatrosses in longline fisheries. Australian Antarctic Division, Tasmania.

Auman, H. J., Ludwig, J. P., Giesy, J. P. and Colborn, T. (1997) Plastic ingestion by Laysan Albatross chicks on Sand Island, Midway Atoll, in 1994 and 1995. Pp. 239-244 in G. Robertson and R. Gales, eds. Albatross biology and conservation. Sydney, Australia: Surrey Beatty and Sons.

Bergin, A. (1997) Albatross and longlining: managing seabird by-catch. Marine Policy 21: $63-72$.

Bjordal, A. and Lokkeborg, S. (1966) Longlining. Oxford, U.K.: Blackwell.

Brothers, N. P. (1991) Albatross mortality and associated bait loss in the Japanese longline fishery in the Southern Ocean. Biol. Conserv. 55: 255-268.

Haward, M., Bergin, A. and Hall, R. (1997) International legal and political bases to the management of the incidental catch of seabirds, in 1994 and 1995. Pp. 255-266 in G. Robertson and R. Gales, eds. Albatross biology and conservation. Sydney, Australia: Surrey Beatty and Sons.

Hayes, E., A. (1997) A review of the southern bluefin tuna fishery: implications for ecologically sustainable management. Sydney, Australia: Traffic Oceania.

Hori, T. (1996) Tuna and the Japanese: in search of a sustainable ecosystem. Japan: JETRO.

Klaer N. and Polacheck, T. (1995) Japanese longline seabird by-catch in the Australin fishing zone April 1991-March 1994: catch and catch rates by area and evaluation of the effectiveness of mitigation measures. Tasmania: CSIRO Div Fisheries Report.

Ludwig, J. P., Summer, C. L., Auman, H. J., Gauger, V., Bromley, D., Giesy, J. P., Rolland, R. and Colborn, T. (1997). The roles of organochlorine contaminants and fisheries bycatch in recent population changes of Black-footed and Laysan Albatrosses in the North 
Pacific Ocean, in 1994 and 1995. Pp. 225-238 in G. Robertson and R. Gales, eds. Albatross biology and conservation. Sydney, Australia: Surrey Beatty and Sons.

Murray, T. E., Bartle, J. A., Kalish, S. R. and Taylor, P. R. (1993). Incidental capture of seabirds by Japanese southern bluefin tuna longline vessels in New Zealand waters 1988-1992. Bird Conserv. Int. 3: 181-210.

\section{GRAHAM ROBERTSON}

Australian Antarctic Division, Channel Highway, Kingston, Tasmania 7050, Australia. 